\title{
Universal Supercritical Binary Mixture for Polymer Fractionation
}

\author{
Stéphanie REY ${ }^{\dagger}$ and François CANSELL ${ }^{\dagger \dagger}$ \\ Institut de Chimie de la Matière Condensée de Bordeaux, \\ CNRS-UPR 9048, Université Bordeaux I, \\ Château Brivazac, 33608 PESSAC cedex-France
}

(Received December 22, 1997)

\begin{abstract}
Supercritical fluids are well known for their efficiency to fractionate polymers as a function of their molar mass, their architecture and their chemical composition, in the case of copolymers. We have used a supercritical solvent mixture, made of $\mathrm{CO}_{2}$ and ethanol, to fractionate poly(ethylene oxide) (PEO) and polystyrene (PS). This mixture which can solubilize both polar (PEO) and nonpolar (PS) polymers, allows the obtention of a narrow molar mass distribution with possibility to select the molar mass value and the molar mass distribution of the extracted sample. The purification of a binary mixture of star and linear PEO has been also performed.
\end{abstract}

KEY WORDS Supercritical Fluid / Polymer / Fractionation / Star Architecture /

Several authors have studied the polymer fractionation with a supercritical fluid processing, during this last decay. ${ }^{1,2}$ The fractionation of polymer chains with narrow molar mass distribution or the extraction of residual monomers, catalytic system, are performed by adjustment of the fluid density which permits a modulation of the solutes solubility (it increases with density) and fluid selectivity (it decreases with density) ${ }^{3,4}$ So uniform and clean materials can be easily and quickly obtained in comparison with ionic polymerization or other separation techniques such as dialysis. As we have shown in a previous paper, by separating star and linear polymers of the same molar masses; the fractionation principle is based on the hydrodynamic volume of polymer chains difference. ${ }^{5}$

Carbon dioxide $\left(\mathrm{CO}_{2}\right)$ is generally used for these studies. Indeed it is recognized as a replacement fluid for environmentally objectionable organic solvents and can be used to reduce their use. ${ }^{6}$ So the investigation of binary mixtures of carbon dioxide with organic solvents is particularly studied in order to develop supercritical fluid processing technology. ${ }^{7,8}$

The present report deals with the fractionation (with respect to the molar masses) of two chemically different polymers, the poly(ethylene oxide) (PEO, polar compound) and polystyrene (PS, nonpolar compound), with a supercritical solvent mixture made of $\mathrm{CO}_{2}$ and ethanol. Other organic cosolvents have also been tested for the PS fractionation.

\section{EXPERIMENTAL}

The experimental apparatus (Figure 1) used for SCF fractionation, up $40 \mathrm{MPa}$ and $400^{\circ} \mathrm{C}$, essentially consists of a high pressure pump (minipump Model 396/2396) and a mass exchanger. The binary mixture (solvent + cosolvent) is pressurised in liquid phase up to the required pressure. Then it flows through a heat exchanger which brings the fluid to the working temperature and through the mass exchanger. The mass exchanger is a column of
$0.8 \mathrm{~cm}$ diameter and $20 \mathrm{~cm}$ length. It is filled with a glass packed bed of $0.2 \mathrm{~cm}$ diameter and polymer. Silica wool is placed at the inlet and outlet of the column to avoid the dragging of polymer by the flowing fluid. The rate is adjusted by a micrometring valve located at the exit of the apparatus. We have worked either at constant temperature with an increasing pressure profile when fractionation as a function of the molar mass was investigated or at constant temperature and pressure to purify star polymers contaminated with linear impurities.

The weight compositions of the supercritical mixtures are determined during each experiment, by means of a flow-meter $\left(\mathrm{CO}_{2}\right.$ part) and a balance (cosolvent part). The flow-meter measures the $\mathrm{CO}_{2}$ flow rate and the balance, the weight of cosolvent pumped during the experiment. Incertitudes for the flow-meter are about $0.4 \%$ and around $1 \mathrm{mg}$ for the balance. Flow rates of $\mathrm{CO}_{2}$ and cosolvent, used in each experiment, are given in the Table I.

The characterization of linear PEO and PS samples was performed by a size exclusion chromatography (SEC) with a refractive index detector. SEC were run with either a water-methanol $(50: 50, \mathrm{v} / \mathrm{v})$ mixture for the PEO or toluene for the PS.

$\mathrm{CO}_{2}$ is provided by Air Liquide. Its critical temperature and critical pressure are respectively $31^{\circ} \mathrm{C}$ and $7.38 \mathrm{MPa}$. Ethanol is a Prolabo product ( $99.9 \%$ purity) and other organic solvents, Aldrich products. The linear PEO samples come from Aldrich, the linear PS from Polymer Expert. Star PEO samples are synthesized in Laboratoire de Chimie des Polymères Organiques.

\section{RESULTS AND DISCUSSION}

\section{Fractionation of $P E O$}

Several linear PEO samples with molar masses from 1000 to $35000 \mathrm{~g} \mathrm{~mol}^{-1}$ were mixed so as to make a compound with a very broad molar mass distribution (Table II).

\footnotetext{
† Tel: +33-556-84-26-73, Fax: +33-556-84-27-61, e-mail: Rey@chimsol.icmcb.u-bordeaux.fr

${ }^{+\dagger}$ Tel, Fax: Same as the above, e-mail: Cansell@ chimsol.icmcb.u-bordeaux.fr.
} 


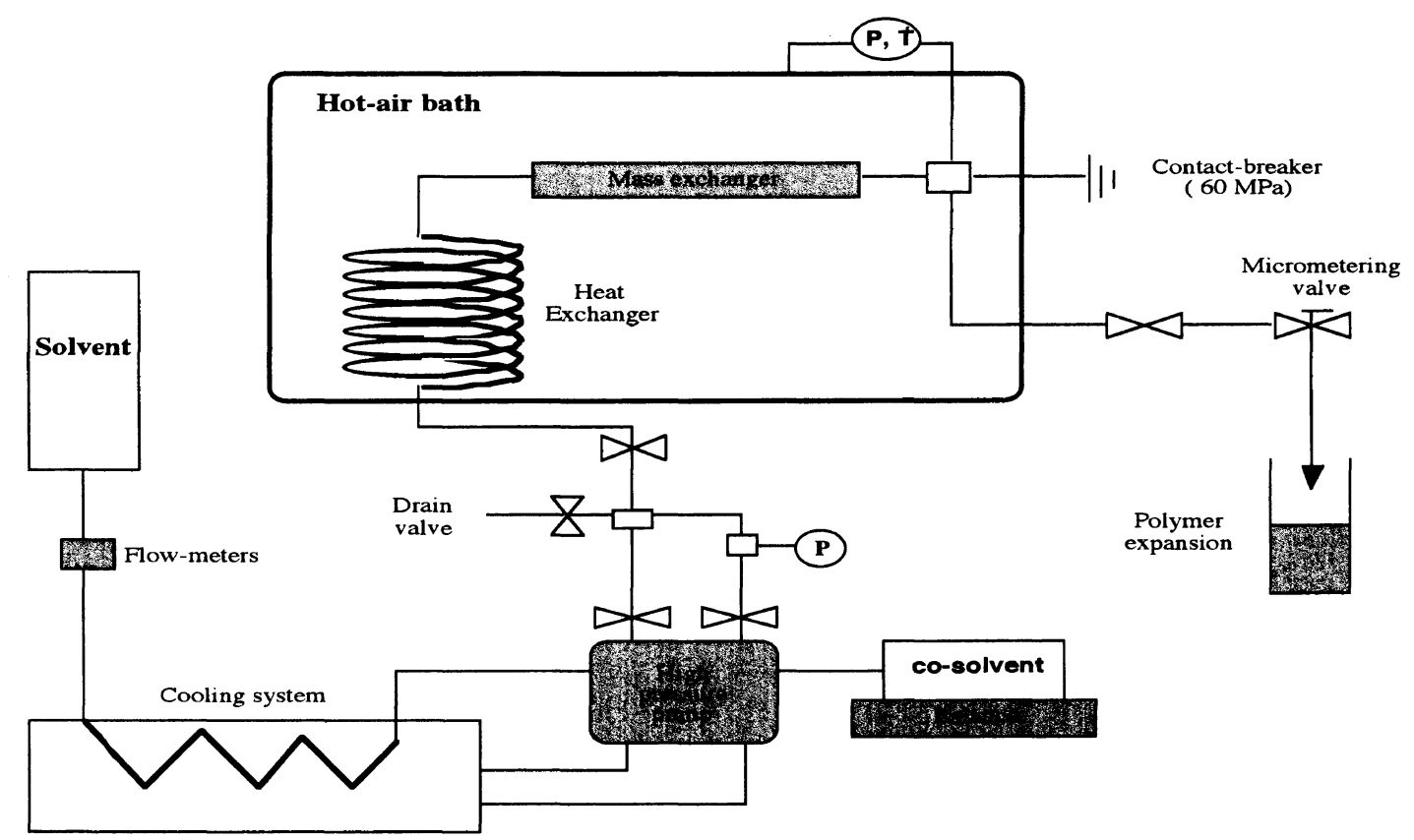

Figure 1. Schematic experimental setup used for the fractionation of polymers with a supercritical binary mixture.

Table I. Binary mixture flow rates used during experiments on PEO and PS fractionation

\begin{tabular}{|c|c|c|c|}
\hline \multirow{2}{*}{ Mixture } & \multirow{2}{*}{$\frac{\mathrm{Co}_{2} \text { flow rate }}{\mathrm{kg} \mathrm{h}^{-1}}$} & \multirow{2}{*}{$\frac{\text { Cosolvent flow rate }}{\mathrm{kg} \mathrm{h}^{-1}}$} & \multirow{2}{*}{$\frac{\text { Total flow rate }}{\mathrm{kg} \mathrm{h}^{-1}}$} \\
\hline & & & \\
\hline $\begin{array}{l}\mathrm{CO}_{2} \text { ethanol } \\
(94: 6 \% \text { in weight })\end{array}$ & 0.155 & 0.011 & 0.166 \\
\hline $\begin{array}{l}\mathrm{CO}_{2} \text {-ethanol } \\
(91: 9 \% \text { in weight })\end{array}$ & 0.162 & 0.014 & 0.176 \\
\hline $\begin{array}{l}\mathrm{CO}_{2} \text { ethanol } \\
(70: 30 \% \text { in weight })\end{array}$ & 0.061 & 0.026 & 0.087 \\
\hline $\begin{array}{l}\mathrm{CO}_{2} \text {-ethanol } \\
(58: 42 \% \text { in weight })\end{array}$ & 0.072 & 0.054 & 0.124 \\
\hline $\begin{array}{l}\mathrm{CO}_{2} \text {-acetone } \\
(58: 42 \% \text { in weight })\end{array}$ & 0.072 & 0.054 & 0.124 \\
\hline $\begin{array}{l}\mathrm{CO}_{2}-\mathrm{THF} \\
\text { ( } 70: 30 \% \text { in weight })\end{array}$ & 0.084 & 0.036 & 0.12 \\
\hline $\begin{array}{l}\mathrm{CO}_{2}-\mathrm{THF} \\
(50: 50 \% \text { in weight })\end{array}$ & 0.061 & 0.061 & 0.122 \\
\hline
\end{tabular}

We chose the nature of the cosolvent as a function of the known solubility in various solvents, in normal conditions of temperature and pressure. ${ }^{9}$ So we worked with a mixture made of $\mathrm{CO}_{2}$ and ethanol (the ethanol ratio varying from 6 to $9 \%$ in weight) at $60^{\circ} \mathrm{C}$ and in a pressure range between 15 and $40 \mathrm{MPa}$ (with $5 \mathrm{MPa}$ pressure increments), during $90 \mathrm{~min}$. We recovered six fractions which have been analyzed by SEC. From chromatograms, we can determine the maximum solubilized molar mass or "cut-off mass" (Mc) of each extracted fraction, at a given pressure. The cut-off mass corresponds to the molar mass of the slice that exhibits the lowest elution volume in the SEC eluogram. Then a calibration curve, showing the evolution of the molar mass of extracted chains with the pressure, can be established for a solvent system, at the working temperature.
Table II. Polymer characteristic (number average molar mass, average molar mass in weight, and molar mass distribution)

\begin{tabular}{ccccc}
\hline \multirow{2}{*}{ Polymer } & \multicolumn{1}{c}{$M_{n}$} & & $M_{w}$ & $\begin{array}{c}\text { Molar mass } \\
\text { distribution }\end{array}$ \\
\cline { 2 - 2 } $\mathrm{g} \mathrm{mol}^{-1}$ & & $\mathrm{~g} \mathrm{~mol}^{-1}$ & \\
\hline PEO & 3050 & & 7480 & 2.5 \\
PS & 4140 & & 7160 & 1.7 \\
\hline
\end{tabular}

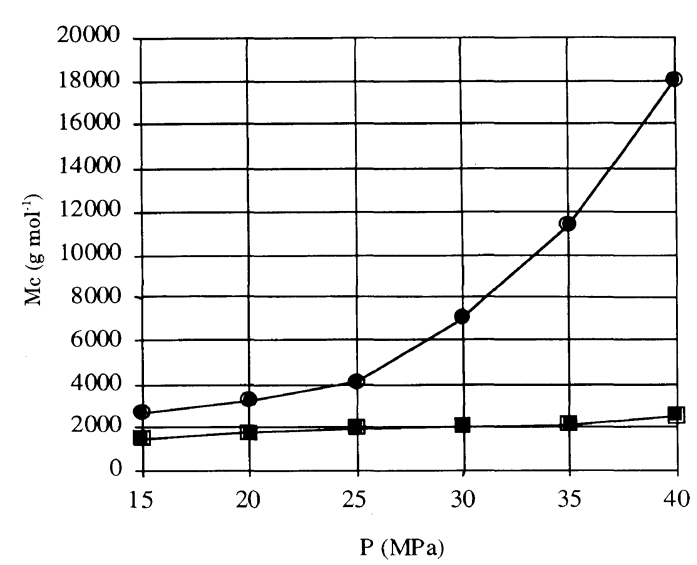

Figure 2. Cut-off-mass of linear poly(ethylene oxide) in supercritical $\mathrm{CO}_{2}$-ethanol $(91: 9$ and $94: 6)$ as a function of the pressure at $60^{\circ} \mathrm{C}$. $-2-, \mathrm{CO}_{2}$-ethanol (91:9 in weight); - - - $\mathrm{CO}_{2}$-ethanol (94:6 in weight).

Experiments were performed with a solvent mixture made of $94 \%$ of $\mathrm{CO}_{2}$ and $6 \%$ of ethanol. This supercritical system does not allow an Mc increase with pressure (Figure 2). For this composition, only the chains of low molar masses are extracted $\left(\approx 2000 \mathrm{~g} \mathrm{~mol}^{-1}\right)$ : the mixture is too selective. From this experiment, we have determined the minimum composition of the solvent mixture. So we have tried a $\mathrm{CO}_{2}$-ethanol mixture (91:9\% in weight), for the second fractionation. In this case, we 


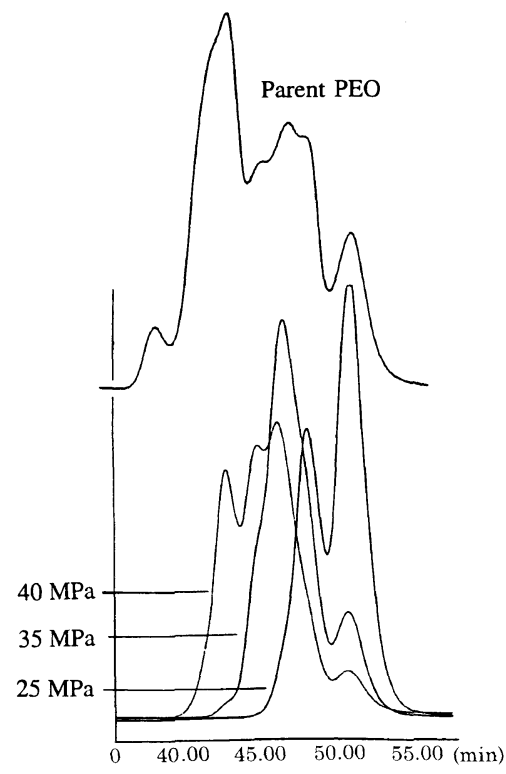

Figure 3. SEC chromatograms of the parent $\mathrm{PEO}$ and representative fractions obtained after fractionation with the supercritical $\mathrm{CO}_{2}$ ethanol mixture (91:9 in weight) at 25,35 , and $40 \mathrm{MPa}$.

can observe a progressive increase of $\mathrm{Mc}$ with the pressure and so with the fluid density (as usually observed) that shows an efficient fractionation ${ }^{10-12}$ (Figures 2 and 3). This experiment is not quantitative but just qualitative. It allows to determine Mc, for a given pressure. The distribution in mass of each recovered fraction has not been optimized $(I=1.2-1.3)$. So in order to decrease the $I$ value, it is necessary to increase the extraction time or to reduce the pressure increments. The Figure 2 reports the calibration curve for the $\mathrm{PEO}-\mathrm{CO}_{2}$-ethanol (91:9\% in weight) system. It permits to define the optimum pressure to apply at $60^{\circ} \mathrm{C}$, for the extraction of PEO of given molar mass. The ethanol ratio cannot be increased above $9 \%$ in weight because it would involve the system demixing, in our temperature and pressure conditions. We then become interested in the separation of PEO as a function of their architecture.

Star PEO samples have been the subject of a great interest because of peculiar properties in solution for biological applications such as coating or vectorisation. As described in the paper, ${ }^{13,14}$ star polymers are prepared via the so-called "core-first" method. This synthesis consists in anionic polymerization of oxirane by means of a plurifunctional metalorganic initiator (alcoholate initiator). As the initiation reaction is quantitative and the functionality of the initiator precisely defined, stars of predetermined size and functionality are directly accessible. However the PEO star samples are often contaminated with linear materials. These linear chains are induced by monofunctional alcoholate that results from the deprotonation of residual protonic impurities present in the reaction medium at the time of the initiation. So a fractionation step is required to eliminate linear PEO. We first tested a mixture made of $50 \%$ in weight of three-arm star $\left(M p=16600 \mathrm{~g} \mathrm{~mol}^{-1}\right)$ and $50 \%$ in weight of linear PEO $\left(M p=3300 \mathrm{~g} \mathrm{~mol}^{-1}\right)$. The fractionation using the $\mathrm{CO}_{2}$-ethanol mixture $(91: 9 \%$ in weight) as supercritical fluid was done at $60^{\circ} \mathrm{C}$ and $27 \mathrm{MPa}$. The value of the pressure to apply was drawn

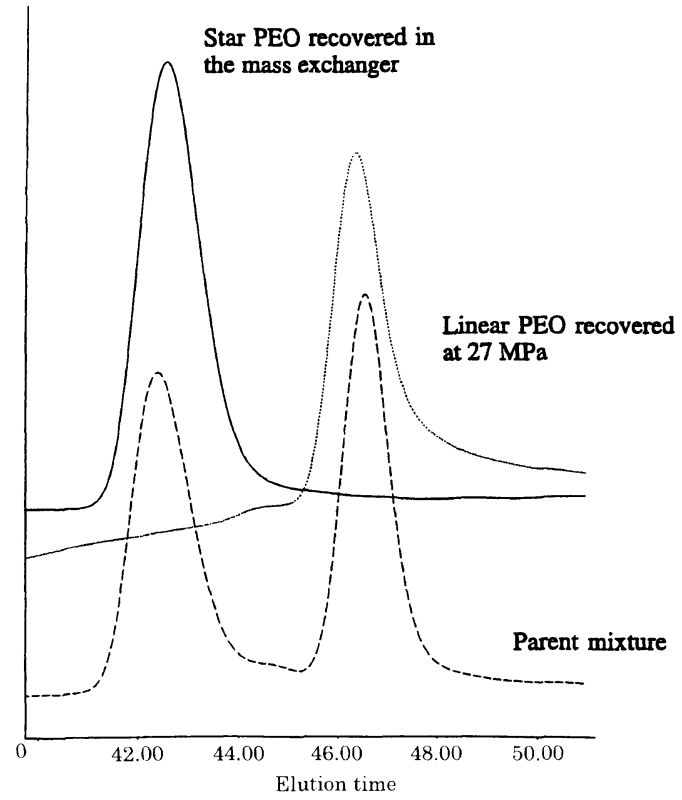

Figure 4. SEC chromatograms of a binary mixture (50:50 in weight) made of linear $\left(M p=3300 \mathrm{~g} \mathrm{~mol}^{-1}\right)$ and star $\left(M p=16600 \mathrm{~g} \mathrm{~mol}^{-1}\right)$ PEO before and after fractionation at $27 \mathrm{MPa}$ and $60^{\circ} \mathrm{C}$.

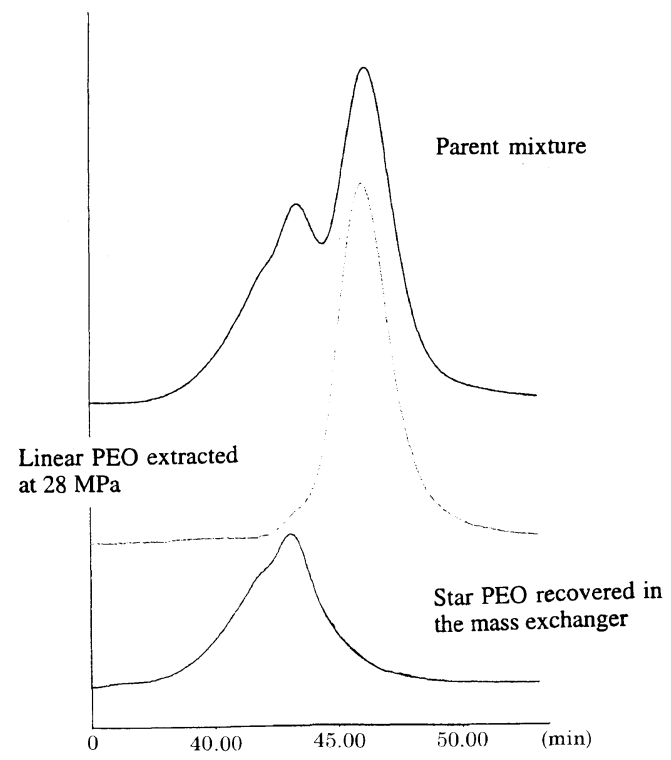

Figure 5. SEC chromatograms of a star PEO $\left(M p=10900 \mathrm{~g} \mathrm{~mol}^{-1}\right)$ contaminated with linear PEO chains $\left(M p=3430 \mathrm{~g} \mathrm{~mol}^{-1}\right)$ before and after fractionation at $28 \mathrm{MPa}$ and $60^{\circ} \mathrm{C}$.

from the calibration curve established for linear chains (Figure 2). As evidenced in Figure 4, the extraction of linear PEO occurs as expected at $27 \mathrm{MPa}$. Another experiment on a three-arm star PEO $\left(M p=10900 \mathrm{~g} \mathrm{~mol}^{-1}\right)$ contaminated with linear chains $\left(M p=3430 \mathrm{~g} \mathrm{~mol}^{-1}\right)$, was investigated using the same supercritical mixture at $60^{\circ} \mathrm{C}$ and $28 \mathrm{MPa}$. In this case, linear impurity exhibits the same molar mass as that of the star branches. The study was carried out with an initial load of $500 \mathrm{mg}$. At these temperature and pressure, we have recovered $280 \mathrm{mg}$ of linear chains $\left(3430 \mathrm{~g} \mathrm{~mol}^{-1}\right)$, after a working time of $4 \mathrm{~h}$ (Figure 5).

In a previous paper, ${ }^{5}$ we had already reported a work on star and linear PEO separation, with supercritical 


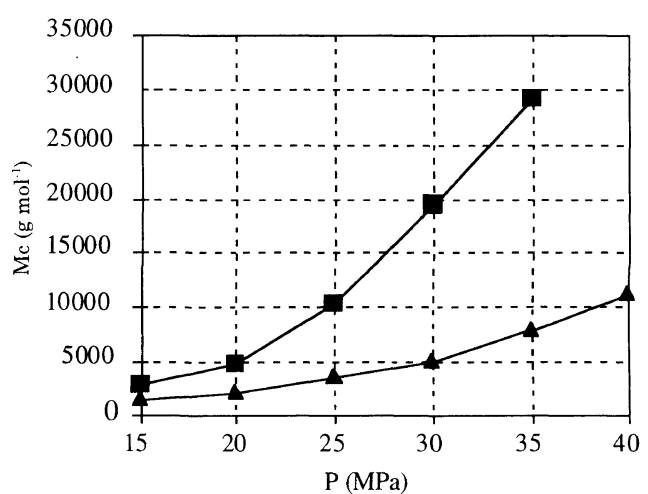

Figure 6. Cut-off-mass of linear polystyrene in supercrtical $\mathrm{CO}_{2}$ THF $(50: 50)$ and $(70: 30)$ as a function of the pressure at $150^{\circ} \mathrm{C}$. $-\mathbf{-}-, \mathrm{CO}_{2}-\mathrm{THF}\left(50: 50\right.$ in weight); - $\mathbf{\Delta -}, \mathrm{CO}_{2}$-THF (70:30 in weight).

1-chloro-1,1-difluoroethane (R142b). The same experimental approach has been employed in the present study, with a new solvent system, the $\mathrm{CO}_{2}$-ethanol mixture. Similar results have been found, but here the separation of linear and star PEO is based on the difference in their molar masses rather than the difference in their chain structures. Moreover this solvent system has been investigated to fractionate another polymer, the PS.

\section{Fractionation of PS}

The polystyrene fractionation was first performed, with a mixture made of $\mathrm{CO}_{2}$ and tetrahydrofuran (THF) (a good solvent of PS at the ambient). Experiments were realized on a broad linear polystyrene (Table II) at $150^{\circ} \mathrm{C}$ and in a pressure range from 15 to $40 \mathrm{MPa}$ (with $5 \mathrm{MPa}$ pressure increments), during $90 \mathrm{~min}$. Around $10 \%$ in weight cosolvent, chromatograms do not present any significant evolution of the molar mass, and fractionation yields are low. So, the THF amount in the mixture was increased up to $30 \%$ and $50 \%$ in weight. The evolution of Mc with the pressure is presented on Figure 6. It clearly shows the continuous tunable effect of supercritical mixture to adjust solubility and selectivity. Indeed, the mixture $70: 30$ in weight permits a high selectivity for lower molar masses whereas the mixture $50: 50$ in weight allows a higher solubility with a lower pressure selectivity.

Properties of some solvents are modified in the supercritical domain like water which can dissolve organic solutes, this is because of the dielectric constant decrease. ${ }^{15}$ So, we have added a poor solvent like ethanol and acetone to $\mathrm{CO}_{2}$ and studied their effects on the polystyrene fractionation. Experiments were performed with $\mathrm{CO}_{2}$-ethanol (70:30 in weight), $\mathrm{CO}_{2}$-ethanol (58:42 in weight) and $\mathrm{CO}_{2}$-acetone (58:42 in weight) on the same polystyrene sample, under the same experimental conditions. First we present SEC chromatograms of the parent PS and of several representative fractions, in the case of the supercritical mixture $\mathrm{CO}_{2}$-ethanol (58:42 in weight) fractionation (Figure 7).

Figure 8 shows that the fractionation efficiency increases with the cosolvent amount. This rise is significant when comparing the $\mathrm{CO}_{2}$-ethanol $(70: 30$ in weight) to the $\mathrm{CO}_{2}$-ethanol (58:42 in weight) systems. Indeed with the $\mathrm{CO}_{2}$-ethanol (70:30 in weight) super-

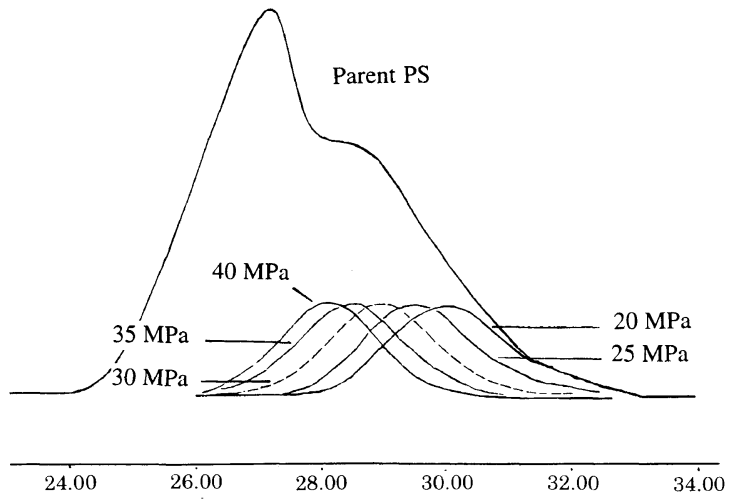

Figure 7. SEC chromatograms of the parent $\mathrm{PS}$ and of representative fractions obtained after fractionation with the supercritical $\mathrm{CO}_{2}$-ethanol mixture (58:42 in weight) at 20, 25, 30, 35, and $40 \mathrm{MPa}$.

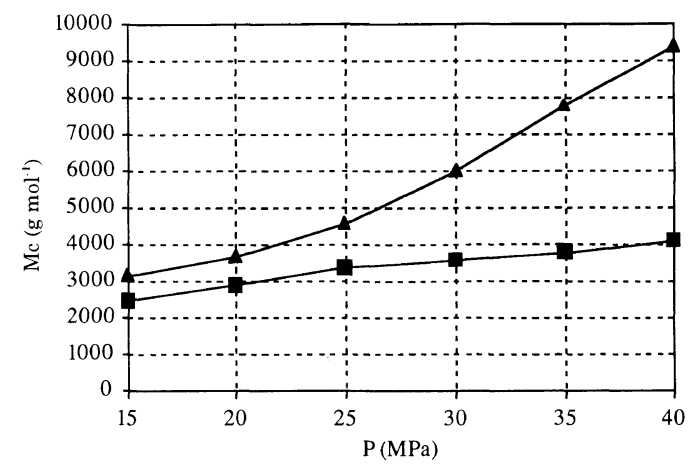

Figure 8. Cut-off-mass of linear polystyrene in supercrtical $\mathrm{CO}_{2}-\mathrm{e}-$ thanol $(58: 42)$ and $(70: 30)$ as a function of the pressure at $150^{\circ} \mathrm{C}$. - $\boldsymbol{\Delta}$ - $\mathrm{CO}_{2}$-ethanol $(58: 42$ in weight $) ;-\mathbf{\square}-, \mathrm{CO}_{2}$-ethanol $(70: 30$ in weight).

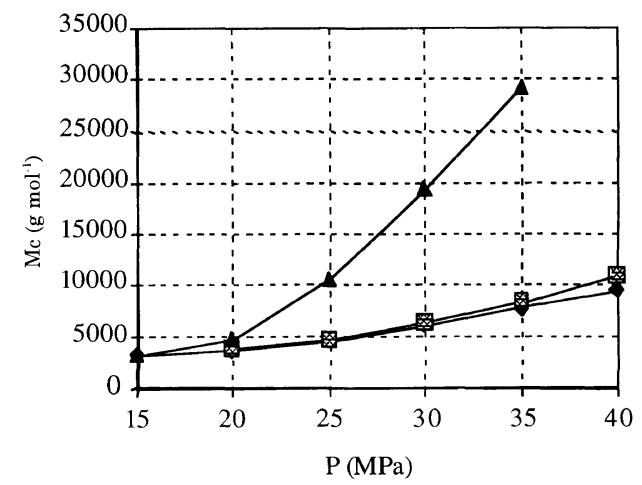

Figure 9. Cut-off-mass of linear polystyrene in supercritical $\mathrm{CO}_{2}$ THF (50:50), $\mathrm{CO}_{2}$-ethanol $(58: 42)$, and $\mathrm{CO}_{2}$-acetone $(58: 42)$ as a function of the pressure at $150^{\circ} \mathrm{C} .--\mathrm{CO}_{2}$-ethanol $(58: 42$ in weight); 一 - $\mathrm{CO}_{2}$-acetone (58:42 in weight); - $\mathbf{-}-, \mathrm{CO}_{2}-\mathrm{THF}$ (50:50 in weight).

critical mixture, the solubilized molar mass increases slowly and weakly whereas the $\mathrm{CO}_{2}$-ethanol $(58: 42$ in weight) system enables to obtain a good Mc increment with the pressure comparable to the effect of the $\mathrm{CO}_{2}-$ THF (70:30 in weight) mixture. These results bear out that THF is a better cosolvent for PS than ethanol and acetone. Indeed at $40 \mathrm{MPa}$, the $\mathrm{CO}_{2}-\mathrm{THF}(50: 50)$ supercritical mixture solubilize molar masses three times high as $\mathrm{CO}_{2}$-ethanol $(58: 42)$ and $\mathrm{CO}_{2}$-acetone $(58: 42)$ systems (Figure 9). Nevertheless, these two last mixtures are competitive and can be used to fractinate samples of low molar masses (from 2000 to $10000 \mathrm{~g} \mathrm{~mol}^{-1}$ ). 
Experiments have shown that the chemical nature of the cosolvent can not be considered as the only key factor of the fractionation efficiency. The cosolvent amount is an important parameter which must be controlled and adjusted in order to optimise the compromise between solubility of the chains and selectivity. Moreover, whatever the cosolvent added to $\mathrm{CO}_{2}$, a good (THF) or a poor solvent (ethanol, acetone) of the PS, it is its amount in the supercritical solvent mixture that will define the molar masses scale to fractionate and the efficiency of the separation. This original behavior can be interpreted as a cluster formation of the cosolvent ${ }^{16}$ when there is a low ethanol amount, as in the PEO solubility case. The PS solubility, which is insoluble in $\mathrm{CO}_{2}$ and ethanol, could be explained by the formation of hydrophobic microdomains resulting from a complex between $\mathrm{CO}_{2}$ and ethanol molecules. ${ }^{17}$

\section{CONCLUSIONS}

Fractionations with supercritical mixtures have been validated as a function of the polymer molar masses, with correct and even good yields in weight and in time, in comparison with the dialysis process. ${ }^{5}$ With a binary mixture, we have a supplementary degree of freedom. We can work, at constant temperature and pressure, and just modulate the cosolvent amount in order to extract chains of different lengths and different chemical natures such as for the copolymer fractionation. The more the cosolvent composition increases, the higher the solubilized molar masses.

It was found that ethanol used as a cosolvent in various amounts, can solubilize chemically different polymers such as polar (PEO) and nonpolar (PS) polymers. This allows to think that the $\mathrm{CO}_{2}$-ethanol system could be used to fractionate whichever polymer. In each case, the only parameters to define would be the mixture composition and the fluid density. This supercritical solvent mixture could be considered as universal.
Now, we study with spectroscopic techniques, the microscopic organization of the mixture which enables to solubilize both hydrophobic and hydrophilic polymers.

Acknowledgments. The authors thank the LCPO (Laboratoire de Chimie des Polymères Organiques) for products and its technical help and the ministry of national education for financial support.

\section{REFERENCES}

1. V. J. Krukonis, Polymer News, 11, 7 (1985).

2. M. A. McHugh, Encyclopedia of Polymer Science and Engineering, 16, 368 (1989).

3. Ph. Botella, F. Cansell, Y. Garrabos, J. L. Six, Y. Gnanou, B. Le Neindre, and R. Tufeu, High Temperatures-High Pressures, 29, 449 (1997).

4. M. Hamedi, P. Desmaret, F. Cansell, and R. Tufeu, Polymer, 39, 347 (1997).

5. F. Cansell, Ph. Botella, J. L. Six, Y. Garrabos, R. Tufeu, and Y. Gnanou, Polym. J., 29, 910 (1997).

6. M. Perrut, "Supercritical Fluids and Environment," D. Barth, J. M. Blanchard, and E. Cansell, Ed., AIPFS Publishing, Nancy, France, 1997, pp 1-10.

7. H. Pöhler and E. Kiran, J. Chem. Eng. Data, 42, 379 (1997).

8. H. Pöhler and E. Kiran, J. Chem. Eng. Data, 41, 482 (1996).

9. J. Brandrup and E. H. Immergut, "Polymer Handbook," 3rd ed, John-Wiley \& Sons, New York, N.Y., 1989.

10. I. Ylgör and J. E. McGrath, Polym. Bull., 12, 491 (1984).

11. K. M. Scholsky, K. M. O'Connor, and C. S. Weiss, J. Appl. Polym. Sci., 33, 521 (1987).

12. W. M. Saltzman, N. F. Sheppard, M. A. McHugh, R. B. Dause, J. A. Pratt, and A. M. Dodrill, J. Appl. polym. Sci., 48, 1493 (1993).

13. E. Cloutet, J. L. Fillaut, D. Astruc, and Y. Gnanou, "Macromolecular Engineering: Contemporary Themes," M. Mishra, Ed., Plenum Press, New York, N.Y., 1995, p 47.

14. Y. Gnanou, P. Lutz, and P. Rempp, Makromol. Chem., 189, 2885 (1988).

15. R. W. Shaw, T. B. Brill, A. A. Clifford, C. A. Eckert, and E. U. Franck, Chem. Eng. News., 69, 26 (1991).

16. G. G. Yee, J. L. Fulton, and R. D. Smith, J. Phys. Chem., 96, $6172(1992)$

17. Y. Dant and M. Besnard, Private communication. 